\title{
Epidemiology of sarcoidosis in Japan
}

\author{
T. Morimoto*, A. Azuma*, S. Abe*, J. Usuki*, S. Kudoh*, K. Sugisaki", \\ M. Oritsu and T. Nukiwa
}

ABSTRACT: The present study was designed to identify recent clinical phenotypes using the National Epidemiological Survey and to compare findings with those of previous surveys in Japan.

Pathologically confirmed sarcoidosis cases newly diagnosed in 2004 were eligible for the present study. Disease parameters were recorded and compared.

A total of 1,027 patients were enrolled from a cluster encompassing $79.4 \%$ of the entire Japanese population. The study participants consisted of 364 males and 663 females, providing an average incidence rate of 1.01 per 100,000 inhabitants ( 0.73 for males and 1.28 for females). The age-specific incidence rate displayed a biphasic pattern in the whole patient population and in the females. The male incidence rates peaked in the 20-34-yr-old group. A second peak for 5060-yr-old females showed a higher incidence than the first younger peak. Patients with abnormalities in eyes, skin and cardiac laboratory findings accounted for 54.8, 35.4 and $23.0 \%$ of cases, respectively. The female/male incidence ratio was increased, and the frequency of eye and skin involvement and cardiac abnormality was higher than in previous surveys conducted in Japan.

In conclusion, the data obtained in the present study differ from those of other countries and showed changes in sarcoidosis clinical phenotypes compared with previous studies in Japan.

KEYWORDS: Epidemiology, incidence, Japan, sarcoidosis, sex

$\mathrm{S}$ arcoidosis is a systemic granulomatous disorder of unknown aetiology, involving multiple organs. The disease occurs throughout the world, affecting both sexes and all ethnicities and ages [1]. As the clinical phenotype varies in different areas and among ethnic groups, epidemiological surveys of sarcoidosis are important. However, few recent reports on the epidemiology of sarcoidosis are available, which remains a problematic issue for several reasons, including: 1) lack of a precise and consistent case definition; 2) variable methods of case ascertainment; 3) variability in disease presentation; 4) lack of sensitive and specific diagnostic tests, resulting in under-recognition and misdiagnosis of the disease; and 5) the paucity of systematic epidemiological investigations of cause [2].

Japanese sarcoidosis has a low incidence and prevalence, and is less severe than in western countries [3]. Sarcoidosis in Japan is reported to have a much higher likelihood of ocular and cardiac involvement than in the West [4]. Pulmonary sarcoidosis is recognised as a significant cause of death in western countries, but in Japan it is cardiac lesions that are found to be the main cause of death at autopsy [5, 6]. In 1960, the Clinical Epidemiological Research Committee on Sarcoidosis conducted the first nationwide survey of the disease in Japan, followed by seven other surveys up to 1991 [6]. As there have been no further national epidemiological surveys in Japan since 1991, the current authors decided to undertake the present study.

\section{MATERIALS AND METHODS \\ Patients}

The present study was performed using questionnaires for patients with sarcoidosis established by the public health system. In Japan, the Ministry of Health, Labour and Welfare defines an "intractable" disease as one for which: studies on a national scale are necessary, as it is unidentified; treatment is extremely difficult; it is a chronic disease; medical costs are high; and there are few cases. According to this definition, sarcoidosis has been designated an intractable disease since 1974. A total of 123 diseases are currently considered intractable and patients suffering from one of 45 of these (e.g. systemic lupus erythematosus, Crohn's disease or idiopathic interstitial pneumonia) receive financial assistance from the country, provided that they consent to their clinical data being used for research purposes. If the questionnaire submitted

\section{AFFILIATIONS}

${ }^{*}$ Dept of Internal Medicine, Divisions of Pulmonary Medicine, Infectious Diseases and Oncology, Nippon Medical School, and, "Dept of Respiratory Medicine, Japanese Red Cross Medical Centre, Tokyo,

\#Dept of Internal Medicine,

Nisibeppu National Hospital, Beppu, and

${ }^{+}$Dept of Respiratory Oncology and Molecular Medicine, Institute of Development, Ageing and Cancer, Tohoku University, Sendai, Japan.

\section{CORRESPONDENCE}

A. Azuma

Dept of Internal Medicine

Divisions of Pulmonary Medicine

Infectious Diseases and Oncology

Nippon Medical School

1-1-5 Sendagi

Bunkyouku

Tokyo

Japan

113-8603

Fax: 81356853075

E-mail: a-azuma@nms.ac.jp

Received:

June 212007

Accepted after revision:

September 292007

STATEMENT OF INTEREST

None declared.

European Respiratory Journal

Print ISSN 0903-1936

Online ISSN 1399-3003 
by the patient is accepted as indicating sarcoidosis, each prefecture and the government support the medical costs of treatment. The attending physicians are requested to provide clinical information and the questionnaire must be updated every year. The questionnaires are collected in each prefecture and all prefectures enter the clinical information into a central database at the Ministry of Health, Labour and Welfare; however, at the time the present study was conducted, only 34 out of 47 prefectures had actually carried this out.

Patients enrolled in the study were those newly accepted as sarcoidosis cases in 2004. Newly diagnosed cases with a clinical picture and biopsy consistent with sarcoidosis, as assessed by each patient's attending physician and with the agreement of the expert panel in each prefecture, were eligible for the present study. Granuloma of known causes and local sarcoid reactions were excluded. Patients with no histopathological findings were also excluded. The present study was carried out with the permission of the Ministry of Health, Labour and Welfare, which provided the data in anonymous form. Therefore, institutional review board approval for the present study was not sought.

\section{Questionnaires}

The questionnaires included the following items: age, sex, age at onset, ethnicity, familial clustering, reason for seeking medical attention, subjective symptoms, biopsy findings, organ involvement, tuberculin test, angiotensin-converting enzyme, $\gamma$-globulin, serum calcium, urinary calcium, serum lysozyme, gallium scintigram, pulmonary function test, bronchoalveolar lavage fluid and transbronchial lung biopsy. Specific findings of eye involvement in all patients were evaluated by ophthalmologists.

\section{Statistics}

Groups were compared using Chi-squared analysis. Data are expressed as mean $\pm \mathrm{SD}$. Since p-values $<0.05$ could be expected by chance and can only be taken as suggestive of associations, and $\mathrm{p}<0.01$ provides some evidence and $\mathrm{p}<0.001$ stronger evidence of association, a p-value $<0.01$ was considered statistically significant.

\section{RESULTS}

The present authors were able to obtain questionnaires from 34 out of the 47 prefectures of Japan (total population 101,404,000, which represents $79.4 \%$ of the Japanese population in 2004). The number of newly registered sarcoidosis patients accepted as having this intractable disease in 2004 was 1,679, of which 652 presented with insufficient histopathological findings and were excluded from the analysis. Therefore, a total of 1,027 patients with sarcoidosis were enrolled in the present study. Their characteristics are presented in table 1 . The study population was ethnically homogeneous (99.6\% Japanese) and consisted of 364 males and 663 females.

\section{Incidence rate}

The average incidence rate was 1.01 per 100,000 inhabitants, 0.73 for males and 1.28 for females. The age-specific incidence rate is shown in figure 1, displaying a biphasic pattern, with the first peak at 25-34 yrs and the second at 60-64 yrs. The first peak and the second peak were of almost the same frequency. The disease was found in all age groups ( $0-86$ yrs), but only very rarely in individuals aged $<20$ or $>80$ yrs $(0.9$ and $0.4 \%$ of all cases, respectively). Age-specific incidence rates peaked in $20-34$-yr-old males, and only $0.6 \%$ of cases were $<20$ yrs old. No cases were observed in males aged $>80$ yrs. Age-specific incidence rates in females showed a biphasic pattern with a first peak in 25-39-yr-olds and a second in females in their 50s and 60s. This second peak was approximately twice the size of the first peak. Only $1 \%$ of female patients were $<20$ yrs old and $0.7 \%$ were $>80$ yrs old. Familial sarcoidosis, defined as having a first or second degree relative afflicted by the disease, was found in $1.8 \%$ of cases.

\section{Reason for visiting the hospital}

Regarding the initial reason for visiting the hospital, subjective symptoms were the most frequent cause $(56.5 \%)$, and these were observed more often in females than males $(62.8 \%$ in

\begin{tabular}{|c|c|}
\hline \multicolumn{2}{|l|}{ TABLE 1} \\
\hline \multicolumn{2}{|l|}{ Incidence ${ }^{\#}$} \\
\hline All & 1.01 \\
\hline Male & 0.73 \\
\hline Female & 1.28 \\
\hline \multicolumn{2}{|l|}{ Sex } \\
\hline Total & 1027 \\
\hline Female & $663(64.6)$ \\
\hline Male & $364(35.4)$ \\
\hline \multicolumn{2}{|l|}{ Ethnicity } \\
\hline Total & 782 \\
\hline Japanese & 779 (99.6) \\
\hline Other & $3(0.4)$ \\
\hline \multicolumn{2}{|c|}{ Reason to visit hospital } \\
\hline Total & 1002 \\
\hline Male & 357 \\
\hline Female & 645 \\
\hline \multicolumn{2}{|l|}{ Health check } \\
\hline All & $281(28.0)$ \\
\hline Male & $148(41.5)$ \\
\hline Female & $133(20.6)$ \\
\hline \multicolumn{2}{|l|}{ Symptoms } \\
\hline All & $566(56.5)$ \\
\hline Male & $161(45.1)$ \\
\hline Female & 405 (62.8) \\
\hline \multicolumn{2}{|l|}{ Other } \\
\hline All & $163(16.3)$ \\
\hline Male & $52(14.6)$ \\
\hline Female & $111(17.2)$ \\
\hline Familial clustering & $18(1.8)$ \\
\hline Total & 992 \\
\hline Father & 1 \\
\hline Mother & 1 \\
\hline Brother & 3 \\
\hline Sister & 6 \\
\hline Daughter & 1 \\
\hline Aunt & 2 \\
\hline Not described & 4 \\
\hline
\end{tabular}

Data are presented as $\mathrm{n}$ or $\mathrm{n}(\%) .{ }^{*}$ : per 100,000 inhabitants; $"$ : eight doublechoice cases. 

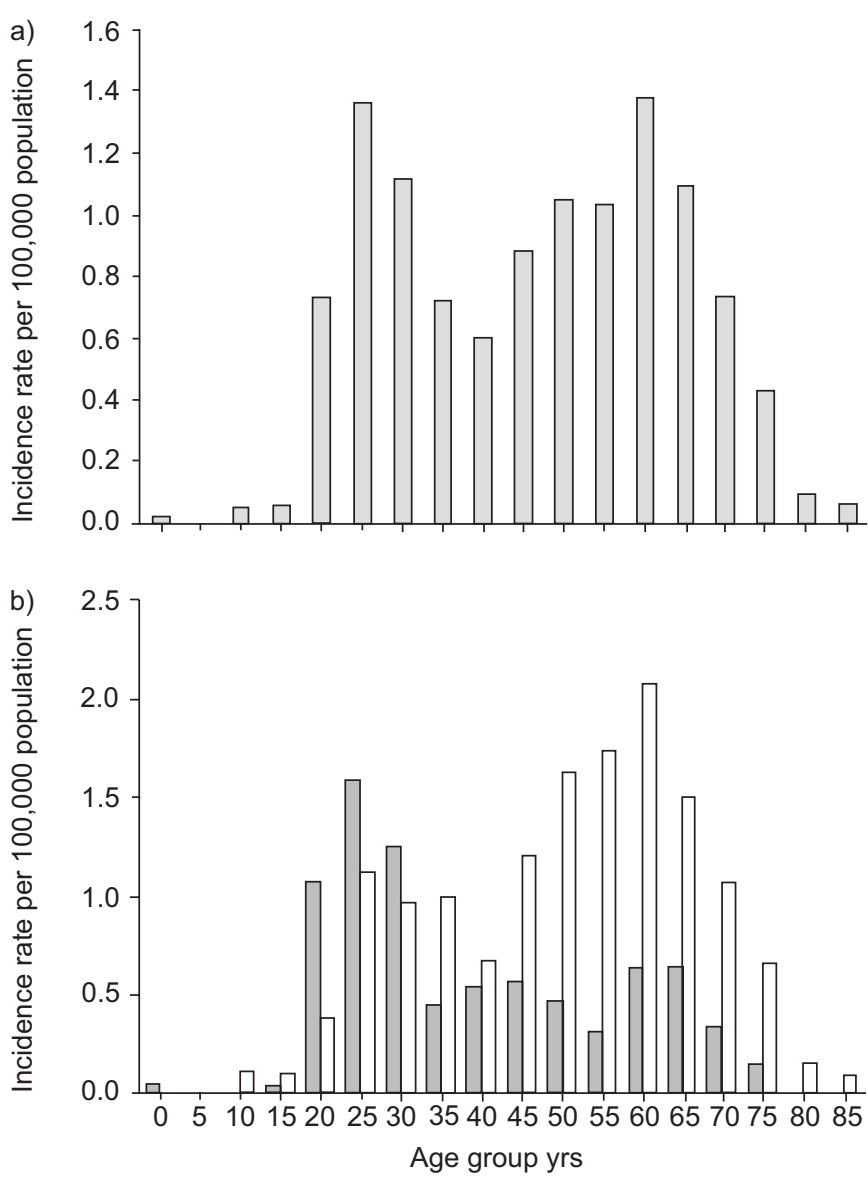

FIGURE 1. Incidence rate of sarcoidosis per 100,000 population stratified by a) age at diagnosis and b) sex. 1 : male; $\square$ : female. The total number of subjects was 938 .

females). Abnormalities detected at routine medical examination and subjective symptoms were similarly frequently found in males as their reason for visiting the hospital (41.5 and $45.1 \%$, respectively). At the time of their first visit to the hospital, subjective symptoms were recorded in $73.9 \%$ of all patients $(78.8 \%$ in females versus $65.1 \%$ in males; $\mathrm{p}<0.0001)$ and the remaining $26.1 \%$ of cases were asymptomatic.

\section{Subjective symptoms and organ involvement}

Subjective symptoms and organ involvement are described in table 2. A total of 309 patients have ocular symptoms and 364 have respiratory symptoms. Females were more likely to have visual disturbance than males (33.2 versus 20.7\%, respectively; $\mathrm{p}<0.0001)$. Approximately $184(17.9 \%)$ had single organ involvement, with most patients limited within the thorax; $843(82.1 \%)$ patients had multiple organ involvement.

Details of the pulmonary and ocular lesions are provided in table 3. Diffuse shadows in the lung field were significantly higher in males $(55.3 \%, p<0.0001)$. Vital capacity $<80 \%$ predicted was found in $9.0 \%$ of cases.

The frequency of abnormal findings concerning the eyes $(p<0.0001)$, uveitis $(p<0.0001)$ and visual disturbance $(p=0.0009)$ was significantly higher in females than males.

\begin{tabular}{|c|c|c|c|c|}
\hline & All & Male & Female & p-value \\
\hline Patients $\mathbf{n}$ & 1001 & 357 & 644 & \\
\hline Asymptomatic & 262 (26.2) & $125(35.0)$ & $137(21.3)$ & $<0.0001$ \\
\hline Symptomatic & 739 (73.8) & $232(65.0)$ & 507 (78.7) & $<0.0001$ \\
\hline Eyesight & $288(28.8)$ & $74(20.7)$ & $214(33.2)$ & $<0.0001$ \\
\hline Cough & $183(18.3)$ & 69 (19.3) & $114(17.7)$ & 0.5238 \\
\hline SOB & $124(12.4)$ & $44(12.3)$ & $80(12.4)$ & 0.9643 \\
\hline Skin & $96(9.6)$ & $19(5.3)$ & $78(12.1)$ & 0.0005 \\
\hline Fatigue & $66(6.6)$ & $19(5.3)$ & $47(7.3)$ & 0.2275 \\
\hline Fever & $61(6.1)$ & $22(6.2)$ & $39(6.1)$ & 0.9462 \\
\hline Chest pain & $41(4.1)$ & $17(4.8)$ & $24(3.7)$ & 0.4286 \\
\hline Neuro-muscle & $34(3.4)$ & $7(2.0)$ & $28(4.3)$ & 0.0490 \\
\hline Eye $^{\#}$ & $21(2.1)$ & $7(2.0)$ & $15(2.3)$ & 0.7038 \\
\hline Lung & $16(1.6)$ & $7(2.0)$ & $9(1.4)$ & 0.4957 \\
\hline Arthralgia & $15(1.5)$ & $5(1.4)$ & $9(1.4)$ & 0.8498 \\
\hline Lymph node $^{+}$ & $12(1.2)$ & $3(0.8)$ & $8(1.2)$ & 0.7551 \\
\hline Weight loss ${ }^{+}$ & $8(0.8)$ & $7(2.0)$ & $1(0.2)$ & 0.0069 \\
\hline
\end{tabular}

Details of the skin, cardiac and other lesions are shown in table 4. Patients with eye abnormalities, skin problems and cardiac laboratory findings constituted $54.8,35.4$ and $23.0 \%$ of cases, respectively. Abnormal findings for skin $(\mathrm{p}<0.0001)$, subcutaneous nodule $(\mathrm{p}<0.0001)$, cutaneous nodule $(p=0.0009)$ and muscle involvement $(p=0.0087)$ were significantly more frequent in females. Abnormal heart-related findings were not significantly different in males and females. However, erythema nodosum $(\mathrm{p}=0.0335)$ and nervous system abnormalities $(p=0.0182)$ were slightly less frequent in females, while abnormal kidney findings were slightly less frequent in males $(p=0.0119)$.

\section{Laboratory findings}

Details of the laboratory findings are given in table 5. Abnormal uptake of gallium was detected by scintigraphy in $87.6 \%$ of 565 patients tested. Tuberculin skin testing was performed on 614 patients and $73.1 \%$ of these showed negative results. BAL fluid analysis was performed on 533 patients and $81.2 \%$ showed lymphocytosis or an increased CD4/CD8 ratio. Hypercalcaemia was found in $7.4 \%$ and was significantly higher in males than females $(p=0.0051)$.

\section{DISCUSSION}

The clinical phenotype of sarcoidosis, such as which organs are affected, incidence and seriousness, varies according to geography and ethnicity. Therefore, epidemiological surveys are necessary, but there are few recent large scale surveys. National surveys have been carried out in Japan: the first took place in 1960 and the most recent, the eighth, in 1991 [6]. However, the present study is the first large scale investigation carried out in Japan with a detailed analysis of many different parameters. Institutional size, investigation period 
TABLE 3 Incidence of lung and ocular involvement by sex

\begin{tabular}{|c|c|c|c|c|}
\hline Lung & $868 / 1009$ (86.0) & $317 / 361(87.8)$ & $551 / 648(85.0)$ & 0.2220 \\
\hline Lung field abnormality & 463/993 (46.6) & 202/355 (56.9) & 261/638 (40.9) & $<0.0001$ \\
\hline Diffuse shadow & $441 / 1003(44.0)$ & 197/356 (55.3) & $244 / 647$ (37.7) & $<0.0001$ \\
\hline Fibrosis & 81/972 (8.3) & 29/343 (8.5) & 52/629 (8.3) & 0.9194 \\
\hline Chest radiographic staging $n$ & 1001 & 358 & 643 & $<0.0001$ \\
\hline Stage 0 & $143(14.3)$ & $44(12.3)$ & $99(15.4)$ & \\
\hline Stage 1 & $405(40.5)$ & $113(31.6)$ & $292(45.4)$ & \\
\hline Stage 2 & $293(29.3)$ & $136(38.0)$ & $157(24.4)$ & \\
\hline Stage 3 & $79(7.9)$ & $36(10.1)$ & $43(6.7)$ & \\
\hline Vitreous body & 221/965 (22.9) & 64/338 (18.9) & $157 / 627(25.0)$ & 0.0313 \\
\hline Retina & 216/959 (22.5) & 65/339 (19.2) & $151 / 620(24.4)$ & 0.0664 \\
\hline Visual disturbance & 198/96 (20.5) & 49/335 (14.6) & 149/629 (23.7) & 0.0009 \\
\hline Secondary glaucoma & $107 / 757(14.1)$ & $35 / 267(13.1)$ & $72 / 490(14.7)$ & 0.5497 \\
\hline Visual field & 69/931 (7.4) & $21 / 331(6.3)$ & $48 / 600(8.0)$ & 0.3560 \\
\hline Optic nerve & 48/955 (5.0) & $16 / 334(4.8)$ & 32/621 (5.2) & 0.8068 \\
\hline Conjunctiva & 28/962 (2.9) & 6/336 (1.8) & 22/626 (3.5) & 0.1284 \\
\hline Lacrimal gland ${ }^{\#}$ & 23/944 (2.4) & $3 / 327(0.9)$ & 20/617 (3.2) & 0.0269 \\
\hline Orbit ${ }^{\#}$ & $7 / 947(0.7)$ & $1 / 329(0.3)$ & $6 / 618(1.0)$ & 0.4321 \\
\hline
\end{tabular}

Data are presented as $n(\%)$ or $n / N(\%)$, where $n$ represents the number of subjects in the group presenting ocular or lung involvement and $N$ the total number of subjects

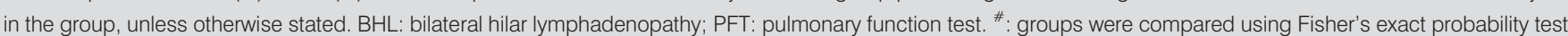

and eligibility criteria (e.g. only new onset or not, exclusively biopsy proven or not) were not identical for all the investigations previously performed. The present study examined newly biopsy-proven sarcoidosis patients in Japan. Even if noncaseous epithelioid cell granuloma is not proven, sarcoidosis patients tend to be diagnosed based on clinical symptoms, course and data from examination. In epidemiological surveys, as it is likely that the incidence rate would be underestimated when including only the biopsy-proven group, clinical diagnosis is important. However, no standard global criteria are available for the clinical diagnosis of sarcoidosis; therefore, only biopsy-proven cases were included for the present study. Data were obtained from an area including $79.4 \%$ of the entire Japanese population and, therefore, consider it likely that these data are representative and reflect the clinical features of Japanese sarcoidosis patients in general. The present study population was homogeneous in terms of ethnicity (99.6\% Japanese), so it was not necessary to examine racial differences.

In the present study, the incidence rate was 1.01 per 100,000 : 0.73 for males and 1.28 for females. The estimated incidence rate in Japan was reported as 1.2 for males and 1.4 for females in both the 1972 and 1984 national surveys [7]. Since only 67.3\% of patients had histological evidence in 1972 and $61.4 \%$ in 1984, it is proposed that the incidence rate for males has remained almost the same over this time period, but increased in females. However, rates cannot be compared directly in different populations as the data are different. For AfricanAmericans, annual sarcoidosis incidence was reported to be as high as 36.5-81.8 per 100,000 [8-10]. In Sweden, the mean total incidence among individuals aged $\geqslant 15$ yrs was 19 per 100,000 per year, 16.5 for males and 21.7 for females [11]. In the USA, a population-based sarcoidosis incidence study revealed rates of 5.9 for males and 6.3 for females per 100,000 inhabitants per year [12]. In the UK, the incidence rate was 5.0, 4.84 for males and 5.24 for females [13]. In Japan, the incidence rate was not as high. In Korea, sarcoidosis is still a very rare disease, although it is increasing slowly, with an incidence rate of 0.125 per 100,000 in 1998 [14]. The reported incidence rate is similarly low in other regions of East Asia, i.e. China, Taiwan and Hong Kong $[3,15,16]$. Consequently, it can be concluded that the incidence of sarcoidosis in the Asian population might be lower than in Caucasian and Black populations.

In previous Japanese studies [6], the female/male incidence ratio was: 0.97 in the period $1960-1964 ; 1.16$ in $1965-1969 ; 1.13$ in 1972; 1.14 in 1973-1977; 1.53 in 1984; and 1.70 in 1991. In the present study, carried out in 2004, the female/male incidence ratio was 1.82 (table 6). Thus, it seems that the female/male 
TABLE 4 Incidence of skin, cardiac and extrapulmonary involvement by sex

\begin{tabular}{|c|c|c|c|c|}
\hline & All & Male & Female & p-value \\
\hline Skin & $358 / 1011$ (35.4) & $89 / 357(25.0)$ & 269/654 (41.1) & $<0.0001$ \\
\hline Subcutaneous nodule & $118 / 978(12.1)$ & 23/348 (6.6) & $95 / 630(15.1)$ & $<0.0001$ \\
\hline Plaque type cutaneous & $87 / 982(8.9)$ & 29/353 (8.2) & $58 / 629(9.2)$ & 0.5946 \\
\hline Erythema nodosum & $61 / 984(6.2)$ & $14 / 350(4.0)$ & $47 / 634(7.4)$ & 0.0335 \\
\hline Heart & 224/976 (23.0) & $91 / 349(26.1)$ & 133/627 (21.2) & 0.0834 \\
\hline ECG & 201/976 (20.6) & 79/349 (22.6) & 122/627 (19.5) & 0.2392 \\
\hline Supraventricular arrhythmia & $69 / 860(8.0)$ & 25/298 (8.4) & 44/562 (7.8) & 0.7736 \\
\hline Bundle branch block & $59 / 858(6.9)$ & 23/295 (7.8) & $36 / 563(6.4)$ & 0.4407 \\
\hline ST-T wave abnormalities & $54 / 824(6.6)$ & $18 / 281(6.4)$ & $36 / 543(6.6)$ & 0.9019 \\
\hline Atrioventricular block & 49/862 (5.7) & $19 / 297(6.4)$ & 30/565 (5.3) & 0.5122 \\
\hline \multicolumn{5}{|l|}{ Other organ } \\
\hline Extrathoracic lymph nodes & $151 / 996(15.2)$ & $55 / 354(15.5)$ & 96/642 (15.0) & 0.8059 \\
\hline Nervous system & $71 / 993(7.2)$ & $16 / 352(4.5)$ & $55 / 641(8.6)$ & 0.0182 \\
\hline Liver & $56 / 995(5.6)$ & $24 / 355(6.8)$ & $32 / 640(5.0)$ & 0.2484 \\
\hline Muscle & 42/993 (4.2) & $7 / 354(2.0)$ & $35 / 639(5.5)$ & 0.0087 \\
\hline Kidney & $36 / 974(3.7)$ & 20/349 (5.7) & $16 / 625(2.6)$ & 0.0119 \\
\hline Parotid gland & $31 / 994(3.1)$ & $11 / 352(3.1)$ & 20/642 (3.1) & 0.9933 \\
\hline Gastrointestinal tract ${ }^{\#}$ & $14 / 891(1.6)$ & $3 / 311(1.0)$ & $11 / 580(1.9)$ & 0.4004 \\
\hline Bone $^{\#}$ & $7 / 961(0.7)$ & $1 / 341(0.3)$ & $6 / 620(1.0)$ & 0.4318 \\
\hline Other & $37 / 850(4.4)$ & 13/303 (4.3) & $24 / 547(4.4)$ & 0.9470 \\
\hline
\end{tabular}

Data are presented as $n(\%)$ or $n / N(\%)$, where $n$ represents the number of subjects in the group presenting skin, cardiac or other organ involvement and $\mathrm{N}$ the total number of subjects in the group, unless otherwise stated. ECG: electrocardiogram. * : groups were compared using Fisher's exact probability test.

ratio has been gradually increasing in Japan since 1960. In A Case Control Etiologic Study of Sarcoidosis (ACCESS) study [17], which enrolled only biopsy-proven patients in the USA, the female/male ratio was 1.74. Many other studies have also reported a slight female predominance [18]. Because the data of this study were self-reported, and females were more likely to have subjective symptoms, the female/male incidence ratio may have been increased.
The disease shows a consistent predilection for adults aged $<40$ yrs, peaking in 20-29-yr-old subjects [17, 19]. The peak age group in the ACCESS study was 35-44 yrs, in the UK it was 30-44 yrs [13,17] and in Scandinavian countries there is a second peak incidence in females aged $>50$ yrs $[11,20,21]$. The age-specific incidence rate displayed a biphasic pattern in the whole population and in females in the present study. The incidence rate for females has been biphasic for a long time in

TABLE 5 Abnormal ratios of laboratory data at diagnosis by sex

\begin{tabular}{|c|c|c|c|c|}
\hline & All & Male & Female & $\mathrm{p}$-value \\
\hline Positive gallium scintigraphy & 495/565 (87.6) & 173/203 (85.2) & 322/362 (89.0) & 0.1968 \\
\hline Negative tuberculin test & 449/614 (73.1) & 161/226 (71.2) & 288/388 (74.2) & 0.4205 \\
\hline Elevated lysozyme & $276 / 473(58.4)$ & 108/183 (59.0) & $168 / 290(58.0)$ & 0.8156 \\
\hline Elevated ACE & 509/981 (51.9) & $182 / 353(51.6)$ & $327 / 628(52.1)$ & 0.8776 \\
\hline Hypercalciuria & 19/298 (6.4) & $8 / 119(6.7)$ & $11 / 179(6.1)$ & 0.8416 \\
\hline
\end{tabular}

Data are presented as $n / N(\%)$, where $n$ represents the number of subjects in the group presenting abnormal ratios of laboratory data and $N$ the total number of subjects in the group. BALF: bronchoalveolar lavage fluid; ACE: angiotensin-converting enzyme. 


\section{TABLE 6 Comparison of previous national epidemiological surveys of sarcoidosis in Japan}

\begin{tabular}{|c|c|c|c|c|c|c|c|c|}
\hline \multirow[t]{2}{*}{ Survey period } & \multirow[t]{2}{*}{ Subjects n } & \multicolumn{4}{|c|}{ Organ involvement \% } & \multicolumn{3}{|c|}{ Reason to visit hospital \% } \\
\hline & & Females & BHL & Lung & Eye & Skin & Health check & Symptom \\
\hline 1960-1964 & 700 & 49.3 & 90.7 & 38.9 & 30.1 & 17.1 & 50.1 & 43.0 \\
\hline 1965-1969 & 1052 & 53.6 & 95.3 & 27.6 & 26.5 & 7.2 & 50.3 & 35.2 \\
\hline 1972 & 330 & 53.0 & 89.3 & 36.3 & 36.8 & 11.7 & 45.2 & 40.7 \\
\hline 1991 & 879 & 63.0 & 75.6 & 29.2 & 49.0 & 18.5 & 29.8 & 64.0 \\
\hline $2004^{\#}$ & 1027 & 64.6 & 75.8 & 46.7 & 54.8 & 35.4 & 28.0 & 56.5 \\
\hline
\end{tabular}

Japan $[7,11,12]$. For females, the first peak was slightly higher in the 1972 national survey than currently. Conversely, the second peak was slightly higher in 1984 and was approximately twice the first peak in the present study. For females, the incidence rate showed a gradual increase when aged $>50$ yrs.

Abnormality at medical examination leading to diagnosis of sarcoidosis has shown a considerable decrease over the years, from $50.1 \%$ in $1960-1964$ to $28.0 \%$ in 2004 , whereas subjective symptoms have increased as the reason for visiting the hospital (table 6). Eyesight disorder was the most frequent symptom $(28.8 \%)$, with a high rate of ocular symptoms (30.9\%). Previous studies in Japan had revealed that ocular symptoms detected at the first medical examination were frequent, at $24.8-38.9 \%$ [6]. Ocular sarcoidosis is becoming more common in Japan [22, 23], and ocular involvement showed a large increase from $30.1 \%$ in $1960-1964$ to $26.5 \%$ in $1965-1969$ and $54.8 \%$ in 2004 (table 6). Previous studies worldwide revealed that the lungs are affected in $>90 \%$ of patients and that dyspnoea, dry cough and chest pain occur in one-third to one-half of all patients [22]. The proportion of patients with bilateral hilar lymphadenopathy decreased from $90.7 \%$ in $1960-1964$ to $95.3 \%$ in $1965-$ 1969 and $75.8 \%$ in 2004. The proportion of patients with pulmonary parenchymal lesions increased slightly. Scadding stage I was the most common followed by stage II, the same pattern as in the ACCESS study [17]. Skin lesions showed a decrease from $17.1 \%$ in $1960-1964$ to $7.2 \%$ in $1965-1969$ and an increase again to $35.4 \%$ in 2004. Erythema nodosum has been reported to have a high frequency in Europeans, but is uncommon in Black individuals and Japanese subjects $[3,22,24]$.

Cardiac sarcoid granulomas and death were significantly more frequent among Japanese sarcoidosis patients than Caucasians and African-Americans [5, 25]. The course of cardiac sarcoidosis is variable and ranges from benign arrhythmias or highdegree heart block to sudden death [22]. A previous study of 320 autopsied cases in Japan [5] revealed that mortality relating to cardiac sarcoidosis was found in $46.9 \%$ of the $194(60.6 \%)$ sarcoidosis-related deaths, but an ante mortem clinical diagnosis of sarcoidosis had been made in only $26.7 \%$ cases. An abnormal electrocardiogram, heart wall motion or myocardial scintigraphy were categorised as abnormalities in cardiac laboratory findings. In the present study, the frequency of patients with abnormalities in cardiac laboratory findings was $23 \%$ (224 out of 979). However, it was not possible to establish the frequency of actual heart sarcoidosis in the present study, so patients with only minor electrocardiogram abnormalities were also included.

It is reported that hypercalcaemia occurs in $10-20 \%$ of sarcoidosis patients worldwide; previous studies in Japan revealed that the rate of hypercalcaemia is $5.1-8 \%$ in this population [26-28]. Hypercalcaemia was significantly higher in males in the present study (10.8 versus $5.5 \%$; $=0.0051)$. In the ACCESS study, abnormalities of calcium metabolism were more frequent among Caucasian subjects, and significantly higher in males [17]. Of 62 patients with hypercalcaemia, calcium in the urine was tested in only $17(27.4 \%)$, of which eight $(47.1 \%)$ showed hypercalciuria. Thus, in this small number of patients where calcium was assayed in both blood and urine, results suggest that there is a divergence between hypercalcaemia and hypercalciuria measurements.

In Japan, the annual tuberculosis incidence was reported as 23.3 per 100,000 in 2004, down from 354.9 per 100,000 in 1964 [29]. Despite this decrease, it is still high compared with other developed nations. Thus, many Japanese are already infected with tuberculosis and the majority of the uninfected have received bacille Calmette-Guerin vaccination. It is reported that the rate of tuberculin skin test negativity in Japan is low at $1.7-20 \%[30,31]$. Therefore, the $73.1 \%$ of sarcoidosis patients with negative tuberculin skin tests is a remarkable finding.

Females were more likely than males to have eye $(p<0.0001)$, skin $(p<0.0001)$, muscle $(p=0.0087)$ and neurological involvement $(p=0.0182)$, as well as hyper- $\gamma$-globulinaemia $(p=0.0169)$. In contrast, males were more likely to have diffuse lung shadow $(p<0.0001)$, hypercalcaemia $(p=0.0051)$ and kidney involvement $(p=0.0119)$. In the ACCESS study, females were more likely to have eye and neurological involvement, and erythema nodosum, whereas males were more likely to have abnormalities in the calcium metabolism. Eye and neurological involvement, and abnormalities of calcium metabolism in the 
present study showed the same pattern as in the ACCESS study, but it is unknown why this should be so. SHARMA [28] reported that there is no evidence of a relationship between sex and hypercalcaemia.

Familial sarcoidosis, defined as having an affected first or second degree relative, was identified in $1.8 \%$ of cases. There have been a number of reports of familial clustering in sarcoidosis, ranging from $1.7-17 \%$ of cases [32]. The eighth national Japanese survey in 1991 identified familial sarcoidosis in $0.7 \%$ of all cases [33]. Although there are thus far limited reports of familial clustering in Japan, there remains the possibility that familial sarcoidosis may gradually increase.

\section{Study limitations}

There are several potential biases in the present study. Data were not extracted from a compulsory disease registry but from self-reported information that may be prone to bias. Subjects who had sarcoidosis manifestations only in locations difficult to biopsy (e.g. eye, brain, heart) might have been excluded from the present study, since confirmatory tissue biopsy was required for diagnosis. The frequency of sarcoidosis involvement in different organs varies by country and ethnicity. It is likely that signs in certain organs (e.g. eye, heart) are more often sought in Japanese sarcoidosis patients than in patients from other parts of the world. Due to the developments in diagnostic techniques (e.g. positron emission tomography scanning for cardiac disease and involvement of other organs), comparisons with previous data cannot be readily made. As there were no clear diagnostic criteria for organ involvement or laboratory data, and the judgement of each attending physician was accepted, diagnostic variability has to be expected. It was not possible to establish reliable information on patient geographical distribution since there was too little data from the southern prefectures. There were also relatively large numbers of missing values, as questionnaires were accepted even when incomplete.

In conclusion, the data obtained in the present study differ from those of other countries and also reveal changes in sarcoidosis clinical phenotypes compared with previous studies in Japan. Because the clinical phenotypes vary by area and ethnicity, and also possibly change with time, epidemiological surveying of sarcoidosis is important for the recognition and diagnosis of the disease. It is necessary that the clinical phenotypes of sarcoidosis are recognised for accurate diagnosis of the disease.

\section{REFERENCES}

1 Newman LS, Rose CS, Maier LA. Sarcoidosis. N Engl J Med 1997; 336: 1224-1234.

2 Hennessy TW, Ballard DJ, DeRemee RA, Chu CP, Melton LJ 3rd. The influence of diagnostic access bias on the epidemiology of sarcoidosis: a population-based study in Rochester, Minnesota, 1935-1984. J Clin Epidemiol 1988; 41: 565-570.

3 James DG. Epidemiology of sarcoidosis. Sarcoidosis 1992; 9: 79-87.
4 Design of a case control etiologic study of sarcoidosis (ACCESS). ACCESS Research Group. J Clin Epidemiol 1999; 52: $1173-1186$.

5 Iwai K, Tachibana T, Takemura T, Matsui Y, Kitaichi M, Kawabata Y. Pathological studies on sarcoidosis autopsy. I. Epidemiological features of 320 cases in Japan. Acta Pathol Jpn 1993; 43: 372-376.

6 Nagai S. [Sarcoidosis-epidemiology and topics.] Nippon Rinsho 2002; 60: 1697-1703.

7 Yamaguchi M, Hosoda Y, Sasaki R, Aoki K. Epidemiological study on sarcoidosis in Japan. Recent trends in incidence and prevalence rates and changes in epidemiological features. Sarcoidosis 1989; 6: 138-146.

8 Gundelfinger BF, Britten SA. Sarcoidosis in the United States Navy. Am Rev Respir Dis 1961; 84: 109-115.

9 Sartwell PE, Edwars LB. Epidemiology of sarcoidosis in the U.S. Navy. Am J Epidemiol 1974; 99: 250-257.

10 Rybicki BA, Major M, Popovich J Jr, Maliarik MJ, Iannuzzi MC. Racial differences in sarcoidosis incidence: a 5-year study in a health maintenance organization. Am J Epidemiol 1997; 145: 234-241.

11 Hillerdal G, Nöu E, Osterman K, Schmekel B. Sarcoidosis: epidemiology and prognosis. A 15-year European study. Am Rev Respir Dis 1984; 130: 29-32.

12 Henke CE, Henke G, Elveback LR, Beard CM, Ballard DJ, Kurland LT. The epidemiology of sarcoidosis in Rochester, Minnesota: a population-based study of incidence and survival. Am J Epidemiol 1986; 123: 840-845.

13 Gribbin J, Hubbard RB, Le Jeune I, Smith CJ, West J, Tata LJ. Incidence and mortality of idiopathic pulmonary fibrosis and sarcoidosis in the UK. Thorax 2006; 61: 980-985.

14 Kim DS. Sarcoidosis in Korea: report of the Second Nationwide Survey. Sarcoidosis Vasc Diffuse Lung Dis 2001; 18: 176-180.

15 Leung WK, Lei KI, Yim A, Sit YK, Lai CK, Leung R. Sarcoidosis in a Hong Kong Chinese woman. Hong Kong Med J 1998; 4: 333-336.

16 Wong CF, Yew WW, Wong PC, Lee J. A case of concomitant tuberculosis and sarcoidosis with mycobacterial DNA present in the sarcoid lesion. Chest 1998; 114: 626-629.

17 Baughman RP, Teirstein AS, Judson MA, et al. Clinical characteristics of patients in a case control study of sarcoidosis. Am J Respir Crit Care Med 2001; 164: 1885-1889.

18 Rybicki BA, Maliarik MJ, Major M, Popovich J Jr, Iannuzzi MC. Epidemiology, demographics, and genetics of sarcoidosis. Semin Respir Infect 1998; 13: 166-173.

19 Gordis L. Sarcoidosis: Epidemiology of Chronic Lung Diseases in Children. Baltimore, The John Hopkins University Press, 1973; pp. 53-78.

20 Alsbirk, PH. Epidemiologic studies on sarcoidosis in Denmark based on a nation-wide central register. A preliminary report. Acta Med Scand Suppl 1964; 425: 106-109.

21 Byg KE, Milman N, Hansen S. Sarcoidosis in Denmark 19801994. A registry-based incidence study comprising 5536 patients. Sarcoidosis Vasc Diffuse Lung Dis 2003; 20: 46-52.

22 Statement on sarcoidosis. Joint Statement of the American Thoracic Society (ATS), The European Respiratory Society (ERS) and The World Association of Sarcoidosis and Other Granulomatous Disorders (WASOG) adopted by the ATS 
Board of Directors and by the ERS Executive Committee, February 1999. Am J Respir Crit Care Med 1999; 160: 736-755.

23 James DG, Neville E, Siltzbach LE. A worldwide review of sarcoidosis. Ann N Y Acad Sci 1976; 278: 321-334.

24 Hosoda Y, Yamaguchi M, Hiraga Y. Global epidemiology of sarcoidosis. What story do prevalence and incidence tell us? Clin Chest Med 1997; 18: 681-694.

25 Iwai K, Sekiguti M, Hosoda Y, et al. Racial difference in cardiac sarcoidosis incidence observed at autopsy. Sarcoidosis 1994; 11: 26-31.

26 Tateno S, Kobayashi Y. [Renal manifestations in sarcoidosis.] Nippon Rinsho 1994; 52: 1613-1618.

27 Berliner AR, Haas M, Choi MJ. Sarcoidosis: the nephrologist's perspective. Am J Kidney Dis 2006; 48: 856-870.
28 Sharma OP. Vitamin D, calcium, and sarcoidosis. Chest 1996; 109: 535-539.

29 The Research Institute of Tuberculosis. Statistics of Tuberculosis 2006. Tokyo, Japan Anti-Tuberculosis Association (JATA), 2006.

30 Noshiro T, Satoh K, Sato H, Miura Y. [Tuberculin survey of university students and postgraduates in 1998.] Kekkaku 2000; 75: 363-368.

31 Hino M, Kudoh S. [The role and meaning of two-step tuberculin skin test among hospital employees.] Jpn J Tuberc Chest Dis 2005; 64: 499-507.

32 McGrath DS, Daniil Z, Foley P, et al. Epidemiology of familial sarcoidosis in the UK. Thorax 2000; 55: 751-754.

33 Yamaguchi M. [Epidemiological study on sarcoidosis in Japan.] Byouri to Rinsho 1995; 13: 762-765. 